\title{
APPLICATION OF GENETIC ALGORITHMS FOR MODELLING THE EDM PARAMETERS ON MACHINING OF AISI 4340 STEEL
}

\author{
Dr. B. James Prasada Rao \\ Professor, KNRCER College, Hyderabad, India \\ Dr. L. Suresh Kumar \\ Mechanical Engineering Department \\ Chaitanya Bharathi Institute of Technology, Telangana, India \\ G Gopal \\ Assistant Professor, SMICH, Hyderabad, India

\section{Jaipal Reddy, Jyothirmayi} \\ Mechanical Engineering Department, Chaitanya Bharathi Institute of Technology, India
}

\begin{abstract}
Every production /manufacturing unit mainly focuses on Productivity and quality which are two important aspects and have become great concerns in today's competitive global market. In the present work, maximizing the Material Removal Rate (MRR) as productivity estimate and minimizing Surface Roughness (SR) is taken as most important output for the Electrical discharge machining (EDM) process. EDM is still an experience process and at the same time selecting optimization and modeling parameters is costly and time consuming. With an intention of these two opposite in nature requirements have been simultaneously satisfied by selecting an optimal process environment (optimal parameter setting). Objective function is obtained by Regression Analysis (RA) and Analysis of Variance (ANOVA) and is optimized using Genetic Algorithm (GA) technique. The model is shown to be effective MRR and SR improved using optimized machining parameters. The material used for the machining is AISI 4340 steel and the electrode material is copper.
\end{abstract}

Key words: Two wheeler Industry, pollution, electric two wheeler, compromises for green benefits, exploring market segments.

Cite this Article: Dr. B. James Prasada Rao, Dr.L. Suresh Kumar, G Gopal, V Jaipal Reddy, Jyothirmayi, Application of Genetic Algorithms for Modelling the EDM Parameters on Machining of AISI 4340 Steel, International Journal of Production Technology and Management (IJPTM), 10(1), 2019, pp. 49-59.

http://iaeme.com/Home/issue/IJPTM?Volume $=10 \&$ Issue $=1$ 


\section{INTRODUCTION}

EDM process utilizes electrical current to disintegrate material from a work piece. The state of the material expelled is controlled to create a protest with wanted geometry and surface qualities. This procedure is normally used to machine hard metals, similar to Titanium and pre $\neg$ hardened Steel[1]. The center idea driving EDM is the capacity of an electric bend to disintegrate the surface of a material. These electric curves shape when the voltage contrast between two firmly isolated items, called cathodes, turns out to be sufficiently expansive to conquer the protection of the hole between them[2]. At the point when this happens, a current of up to 500 A moves through an microscopically little zone, vaporizing the surface of the terminals. This vaporization isolates some material from the bigger work piece, leaving a pit at first glance[4]. As various circular segments happen, this setting disintegrates the surface over a substantial region, forming it in the coveted way.

When designing a part that will be manufactured using an EDM process, one must carefully consider the surface finish required. A fine surface may take several cycles and tool electrodes to achieve[5]. diving up machining and labor costs. Traditional machining techniques should be used for bulk material removal, and EDM for fine details. Figure 1 and 2 gives the detailed process of EDM. The work material used for the Experimentation is AISI 4340 steel and tool is made of copper material[6].

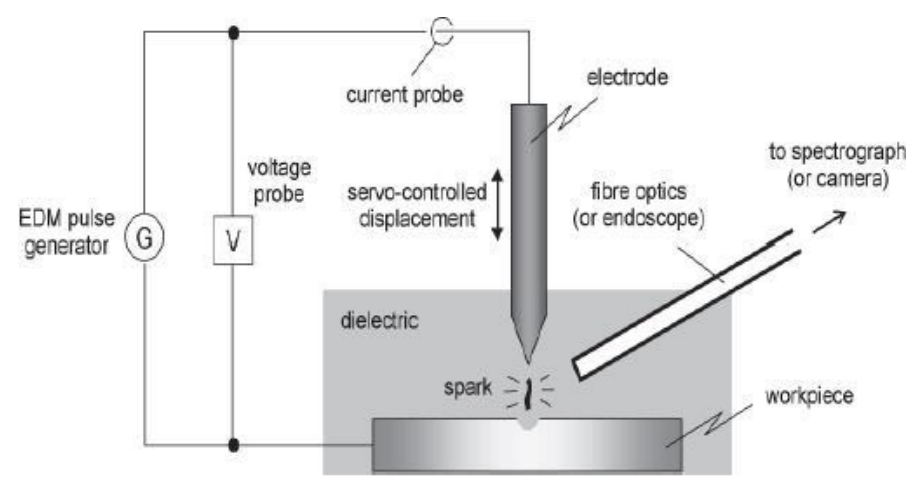

Figure 1 Line diagram of Electric discharge machine

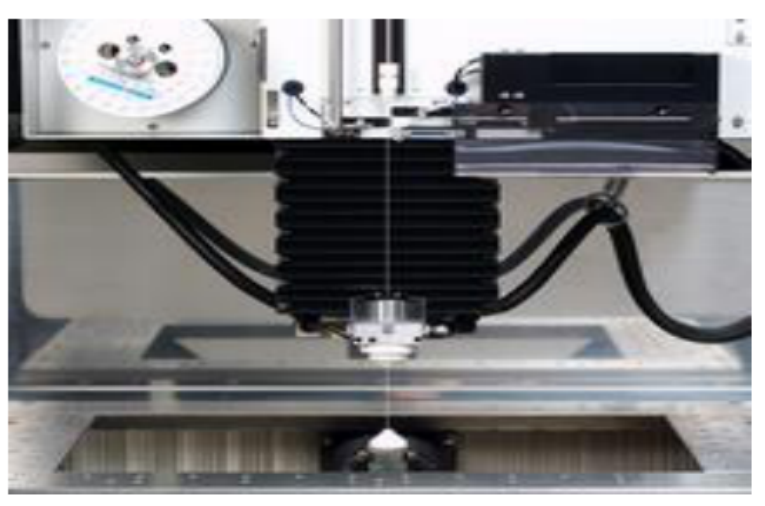

Figure 2 Spark EDM setup

\section{LITERATURE REVIEW}

Modi et al. (2015) studied EDM process parameters so that the whole process Is affected by the electrical and non electrical. The Present work rotating equipment metal removal rate (MRR) to improve And to monitor its impact on surface finish is used .RSM and Taguchi method is used to optimization the design. 
Pradhan et al. (2014) stated that Electrical discharge machining is typically performed based on material removal rate (MRR), tool wear rate (TWR), relative wear ratio (RWR) and surface roughness (SR) is assessed on. EDM machining process performance measures that affect important parameters of the discharging current, Ton time, pulse off time, gap, and are duty cycle. A considerable amount of work MRR, TWR, RWR based on EDM performance measurement, and different materials have been reported by researchers at the SR.Singh et al. (2013) studied the impact on operating parameters such as pulse -time work piece and cryogenic and non -cryogenic DM electrode using steel such as metal removal rate (MRR) and tool wear ratio (TWR) as a response to copper content and pulse time. Cryogenic treatment is increasing material removal rates and tool wear is used to reduce the rate. It was found that the tool wear rate increase with the pulse treatment cryogenic and non cryogenic copper electrode, both electrodes is decreased. Tool wear rate increases with increasing pulse off time. With the increase in time for the $100 \mu \mathrm{s}$ pulse of $50 \mu$ s and $20 \mu$ s to $15 \mu$ s pulse of time with increasing material removal rate increased material removal rate has decreased.

Singh et al. (2012) MRR achieved material different than the material work equipment, such as copper and brass D3 mainly achieved using electrodes. The parameters chosen for the study / off time pulse to pulse. They concluded that the MRR brass electrodes increase with increasing pulse on time. He also found time to MRR copper electrode decreases significantly with the decrease in pulse.

Ponappa et al. (2010) investigated that EDM well geometrically complex parts that are extremely hard materials or traditional machining processes for machining difficult-to-machine building have established election. Regardless of machine stiffness electrically conductive thermal energy into the soil using its unique feature, die, and the automotive, aerospace and manufacturing of components for surgery has its distinct advantages.

Sharma et al. (2010) studied Evaluate the effects of machining alloy aluminum powder MRR,, TWR,\% wear rate by SR using EDMwith reverse polarity

\section{METHODOLOGY}

\subsection{Regression Analysis}

In statistics, regression analysis is a technique developed statistically for estimating the relationships among variables. Most importantly, regression analysis helps one understand how the typical value of the dependent variable changes when any one of the independent variables is varied, with keeping the other independent variables held fixed. Most commonly, regression analysis estimates the conditional expectation of the dependent variable given the independent variables - that is, the average value of the dependent variable when the independent variables are held constant.In every case, the estimation target is a function of the independent variables called the regression function.

\section{Genetic Algorithm Technique}

Genetic algorithm is a robust adaptive optimization technique. Some researchers investigated GA application in EDM. Long back used a multi objective optimization method, nondominating sorting genetic algorithm-II to maximize the result of the process. This provides an optimization model based on genetic algorithms for EDM parameters to imitate a decision.

\section{EXPERIMENTAL RESULTS \& DISCUSSIONS}

For the experimentation on Mixture technique the parameters and their ranges selected are varies from. Experimental data is taken by EDM of work piece material AISI 4340 steel and tool is made of copper material. 
Dr. B. James Prasada Rao, Dr.L. Suresh Kumar, G Gopal, V Jaipal Reddy, Jyothirmayi

Table 1 Levels of parameters selected for experimentation

\begin{tabular}{|c|c|c|c|}
\hline Level & PC(I) & PT(Ton) & DC (Tau) $\%$ \\
\hline Level 1 & 1 & 100 & 50 \\
\hline Level 2 & 5 & 500 & 65 \\
\hline Level 3 & 9 & 1000 & 85 \\
\hline
\end{tabular}

Based on the L9 orthoganal array of Taguchi the experiments are conducted. The outcomes selected for the experiments are MRR and SR.

Table 2 Levels of parameters selected for experimentation

\begin{tabular}{|c|c|c|c|c|c|}
\hline S.No & $\begin{array}{c}\text { Pulse } \\
\text { current } \\
\text { (I)A }\end{array}$ & $\begin{array}{c}\text { Pulse time } \\
\text { (Ton(micr } \\
\text { o sec)) }\end{array}$ & $\begin{array}{c}\text { Duty } \\
\text { cycle(T } \\
\text { au)\% }\end{array}$ & $\begin{array}{c}\text { MRR } \\
\text { (mm3/min } \\
\text { ) }\end{array}$ & SR(um) \\
\hline 1 & 1 & 100 & 50 & 0.24221 & 3.8 \\
\hline 2 & 1 & 500 & 65 & 0.21685 & 7.13 \\
\hline 3 & 1 & 1000 & 85 & 0.10205 & 6.13 \\
\hline 4 & 5 & 100 & 50 & 2.03954 & 7.4 \\
\hline 5 & 5 & 500 & 65 & 2.00242 & 8.6 \\
\hline 6 & 5 & 1000 & 85 & 0.89272 & 7.13 \\
\hline 7 & 9 & 100 & 50 & 5.76275 & 7.8 \\
\hline 8 & 9 & 500 & 65 & 5.58376 & 12.67 \\
\hline 9 & 9 & 1000 & 85 & 5.39 & 12.33 \\
\hline
\end{tabular}

\section{Taguchi Design}

Taguchi Orthogonal Array Design - L9(3^3) Factors: 3 Runs: 9 Columns of L9(3^4) Array 1 23

\section{Taguchi Analysis: MRR (mm3/min versus PC, PT, DC)}

For the MRR, the Larger is better is selected

$$
\begin{array}{lrrr}
\text { Response Table for Signal to Noise Ratios } \\
\text { Level } & \text { PC } & \text { PT } & \text { DC } \\
1 & -15.1389 & 3.0290 & 0.5456 \\
2 & 3.7454 & 2.5643 & 2.5152 \\
3 & 14.9276 & -2.0592 & 0.4733 \\
\text { Delta } & 30.0665 & 5.0882 & 2.0419 \\
\text { Rank } & 1 & 2 & 3
\end{array}
$$

The most influencing factor is current at 9amps followed by PT at 500 micro sec and Dc is $85 \%$. 


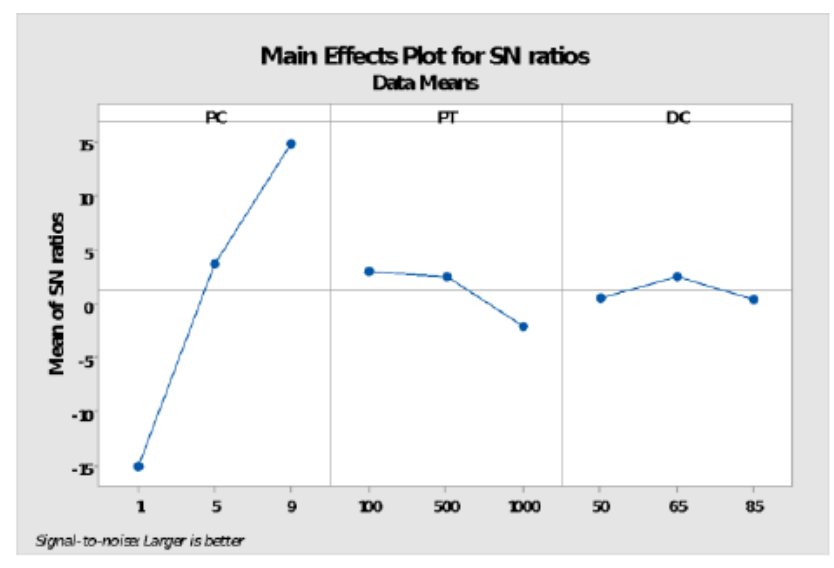

Graph 1 Main Effects Plot for SN ratios

As shown in Graph 1, the top influencing parameter for MRR is Pulse current 9 amps, followed by PT at 500 micro sec and DC is $65 \%$. The most influencing factor is current at 9amps.

Table 3 Taguchi Analysis: SR(um) versus PC, PT, DC

\begin{tabular}{|c|c|c|c|}
\hline \multicolumn{4}{|c|}{ Response Table for S/N ratios } \\
\hline Level & PC & PT & DC \\
\hline 1 & -14.80 & -15.61 & -16.90 \\
\hline 2 & -17.71 & -19.27 & -18.76 \\
\hline 3 & -20.57 & -18.21 & -17.43 \\
\hline Delta & 5.77 & 3.66 & 1.85 \\
\hline Rank & 1 & 2 & 3 \\
\hline
\end{tabular}

\begin{tabular}{|c|c|c|c|}
\hline \multicolumn{4}{|c|}{ Response Table for Means } \\
\hline Level & PC & PT & DC \\
\hline 1 & 5.687 & 6.333 & 7.867 \\
\hline 2 & 7.710 & 9.467 & 8.953 \\
\hline 3 & 10.933 & 8.530 & 7.510 \\
\hline Delta & 5.247 & 3.133 & 1.443 \\
\hline Rank & 1 & 2 & 3 \\
\hline
\end{tabular}

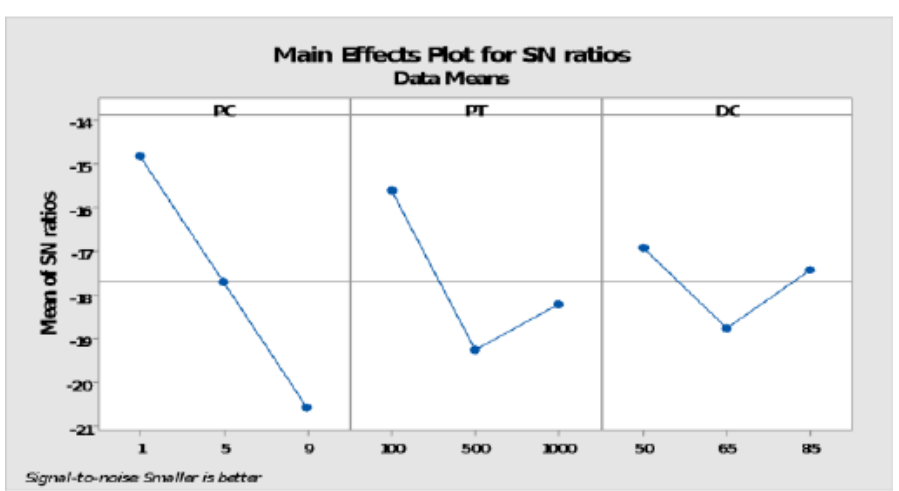

Graph 2 Main Effects Plot for S/N ratios

From Graph 2, the top influencing parameter is Pulse current at 9amps and PT at 500 micro sec and Dc is $65 \%$. 
Dr. B. James Prasada Rao, Dr.L. Suresh Kumar, G Gopal, V Jaipal Reddy, Jyothirmayi

Table 4 Represents the S/N ratio's and mean values of parameters

\begin{tabular}{|c|c|c|c|c|c|c|}
\hline PC & PT & DC & $\begin{array}{c}\text { MRR } \\
(\mathbf{m m 3} / \mathbf{m i n}\end{array}$ & $\begin{array}{c}\text { SR } \\
(\mathbf{u m})\end{array}$ & PSNRA1 & PMEAN1 \\
\hline 1 & 100 & 50 & 0.24221 & 3.8 & -11.9229 & 3.66666 \\
\hline 1 & 500 & 65 & 0.21685 & 7.13 & -17.4355 & 7.88666 \\
\hline 1 & 1000 & 85 & 0.10205 & 6.13 & -15.0483 & 5.50666 \\
\hline 5 & 100 & 65 & 2.03954 & 7.4 & -16.6837 & 6.77666 \\
\hline 5 & 500 & 85 & 2.00242 & 8.6 & -19.0172 & 8.46666 \\
\hline 5 & 1000 & 50 & 0.89272 & 7.13 & -17.4355 & 7.88666 \\
\hline 9 & 100 & 85 & 5.76275 & 7.8 & -18.2156 & 8.55666 \\
\hline 9 & 500 & 50 & 5.58376 & 12.67 & -21.3546 & 12.0466 \\
\hline 9 & 1000 & 65 & 5.39 & 12.33 & -22.1465 & 12.1966 \\
\hline
\end{tabular}

\section{Analysis of Variance (ANOVA)}

Further Analysis of variance is used for validating the Taguchi results and generating the Regression equation.

\section{General Linear Model: MRR(mm3/min versus PC, PT, DC )}

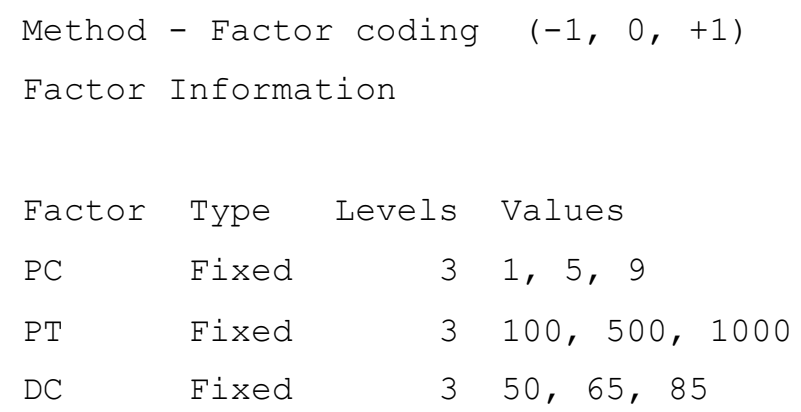

The $\mathrm{R}$ square value is 99.69 and can be considered as optimized validation as the value is between $80-100 \%$. 


\section{Regression Equation}

$\operatorname{MRR}(\mathrm{mm} 3 / \mathrm{min}=2.4703-2.283 \mathrm{PC} 1-0.825 \mathrm{PC} 5+3.109 \mathrm{PC} 9+0.211 \mathrm{PT} 100$

+0.131 PT_500-0.342 PT_1000 -0.231 DC_50 +0.079 DC_6 $\overline{5}+0.152$ DC_ $\overline{8} 5$

\section{General Linear Model: SR (um) versus PC, PT, DC}

Method

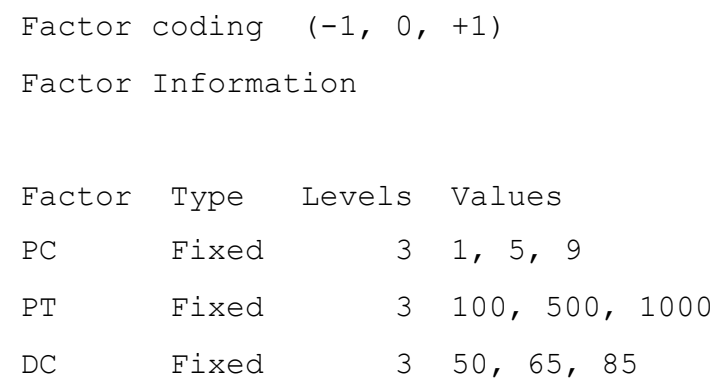

The R square value obtained is $95.40 \%$ and can be considered as optimized validation between 90 to $100 \%$.

\section{Regression Equation}

$\mathrm{SR}(\mathrm{um})=8.110-2.423 \mathrm{PC} \_1-0.400 \mathrm{PC} 5+2.823 \mathrm{PC} \_9-1.777 \mathrm{PT} \_100+1.357 \mathrm{PT}$ 500+0.420PT_10000.243 DC_50+0.843 DC_65-0.600DC_85

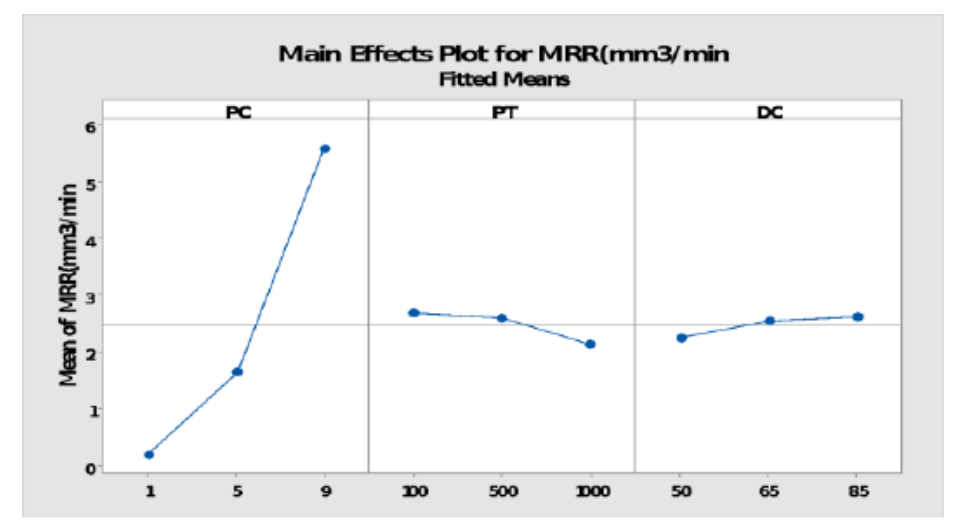

Graph 3 Main effect plot for MRR generated by ANOVA 


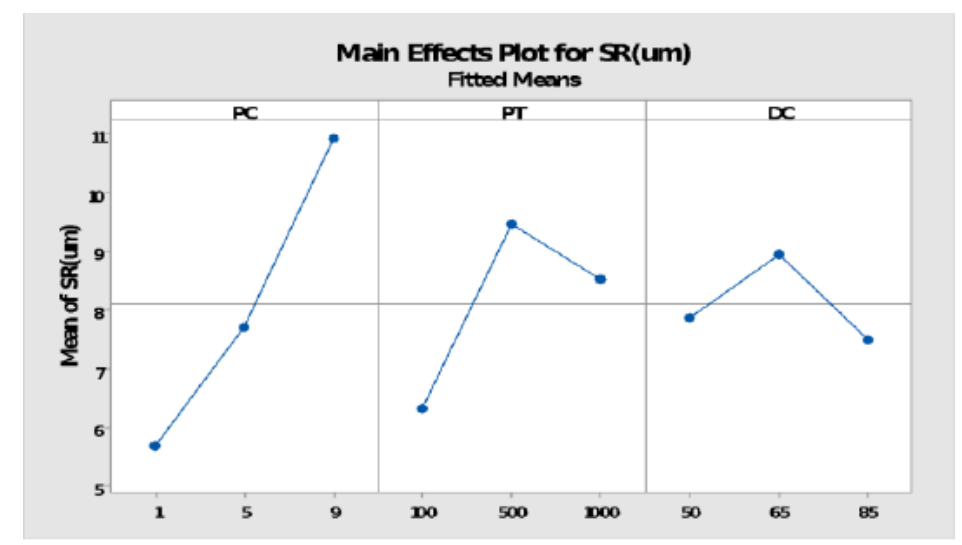

Graph 4 Main effect plot for SR generated by ANOVA

\section{Response Optimization: SR(um), MRR(mm3/min}

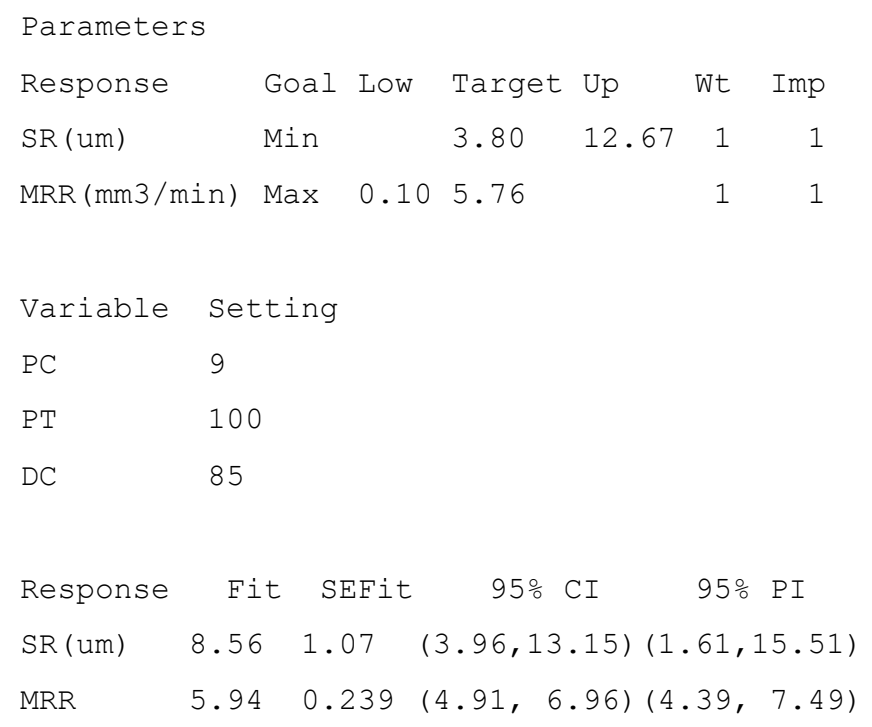

\section{Optimizing by Genetic Algorithm Technique}

Objective function for optimized estimation of Material removal rate is Regression equation for 1. $\mathrm{MRR}=-1.27+0.674 \mathrm{Ip}-0.000631$ Ton +0.0106 Tau And this MRR equation has got Rsq value of $99.56 \%$

Though there is lack of fit, being $\mathrm{R}$-sq value $76 \%$ equation is taken as the regression equation. 2. $\mathrm{SR}=4.71+0.656 \mathrm{Ip}+0.00227$ Ton -0.0169 tau. 25

These equations are optimized using genetic algorithm in mat lab software tool box With current iteration 51: Objective function value: -6.305492566257689

The optimized MRR is obtained at for the values 9.997, 100.114 and 84.993 of Ip, Ton, Tau respectively.

Max and min boundary conditions are $[1,100,50]$ and $[10,1000,85]$.

For Surface roughness: Objective function value: 4.22814646450867 , at the values, 1,100 and 80.766 of Ip, Ton and Tau respectively.

The graphs for best fitness of MRR are shown on Figure 


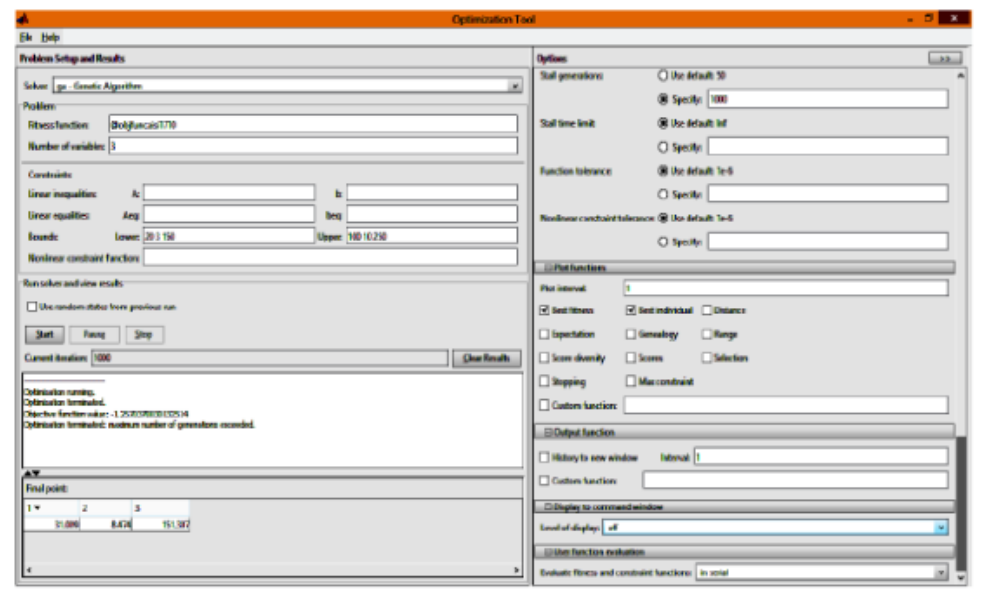

Figure 3MATLAB Optimization Toolbox for AISI 4340 Steel

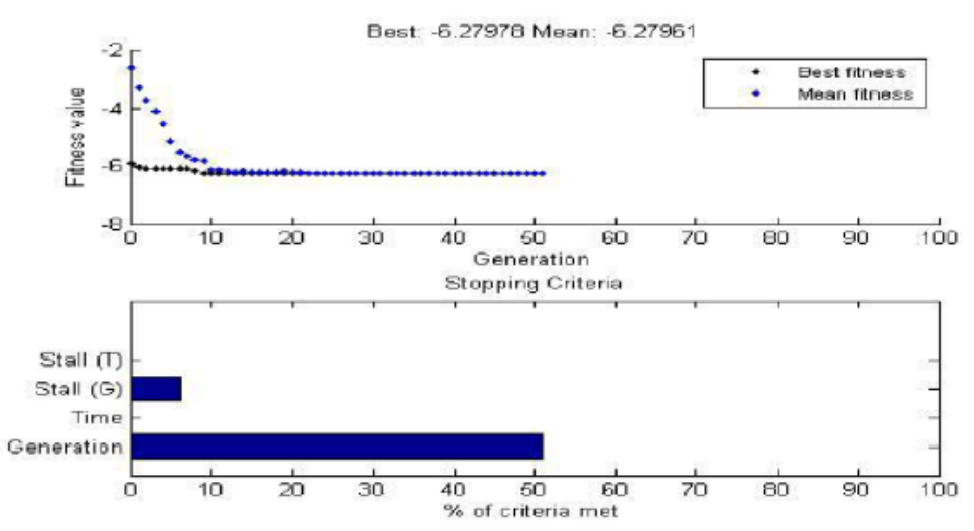

Graph 5 MRR best fitness and stopping criteria graphs

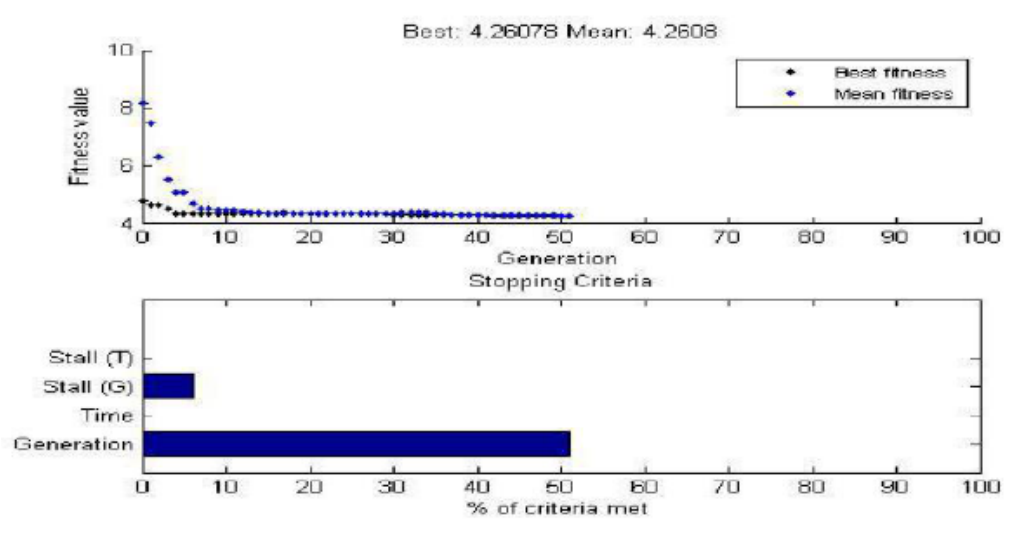

Graph 6 Best fitness and Stopping graphs of SR

Shows the prediction of best fitness value using GA. The initial variation in the curve is due to the search for an optimal solution. It is evident that a minimum combined objective function at -1.257 was observed in the $84^{\text {th }}$ iteration and converges to the same value upto $1000^{\text {th }}$ iteration.

Figure shows the best individual parameter for pulse on time

in variable no. 1 , peak current in variable no. 2 and DC in variable no. 3

for achieving maximum MRR, minimum SR. 
Confirmation Experiment had been conducted for the set of optimal input parameters and the responses MRR, EWR and SR are measured. The EDM machine used for this experiment did not have the provision to set

Ton $=31.009 \mu \mathrm{s}, \mathrm{Ip}=8.474 \mathrm{~A}$ and Toff $=151.307 \mu \mathrm{s}$.

Thus, the input parameters had been set at Ton $=30 \mu \mathrm{s}$ Ip $=8$ A and Toff $=150 \mu$ s.

Experimental values of the outputs are shown in Table

The experimental results are $\mathrm{MRR}=5.762 \mathrm{~mm} 3 / \mathrm{min}, \mathrm{SR}=3.8 \mu \mathrm{m}$.

Table 5 Comparision of GA with Experimental result

\begin{tabular}{|c|c|c|c|c|}
\hline S. No & Responses & GA & $\begin{array}{c}\text { Exp. } \\
\text { value }\end{array}$ & $\begin{array}{c}\text { Absolute } \\
\text { Error }\end{array}$ \\
\hline 1 & MRR (mm3/min) & 5.0724 & 5.762 & 0.687 \\
\hline 2 & SR (micrometers) & 4.67 & 3.8 & 0.87 \\
\hline
\end{tabular}

\section{CONCLUSIONS}

The R square value obtained is $95.40 \%$ and any value between 90 to $100 \%$ can be considered as optimized validation. The optimal parameters are $\mathrm{PC}(1), \mathrm{PT}(2), \mathrm{DC}(3)$ ranking are to be considered as best optimal values as per touchy. The same is compared with GA.

1. Main objective is to maximize MRR and minimize SR of the AISI 4340 Steel work piece and by Genetic Algorithm technique results obtained are: With terminating current iteration 51: Objective function value: -6.305492566257689

2. The optimized Material removal rate is obtained at for the values 9.997, 100.114 and 84.993 of Ip, Ton, Tau respectively. Max and min boundary conditions are $[1,100,50]$ and $[10,1000$, 85].

3. Similarly for Surface roughness:

Objective function value: 4.22814646450867 at the values 1,100 and 80.766 of Ip, Ton, Tau

\section{REFERENCES}

[1] Cao, F.G., and Yang, D.Y., 2004, "The study of high efficiency and intelligent optimization system in EDM sinking process," Journal of Materials Processing Technology, 149(1-3), pp. 83-87.

[2] Lee H.T, Hsu F.C., and Tai T.Y., 2004, "Study of surface integrity using the small area EDM process with a Copper-Tungsten electrode," MATERIAL SCIENCE and ENGINEERING, A364, pp. 346-356.

[3] Karthikeyan, R., Lakshmi Narayanan, P.R. and Naagarazan, R.S., 1999, "Mathematical modelling for electric discharge machining of aluminium-silicon carbide particulate composites," Journal of Materials Processing Technology, 87(1-3), pp. 59-63.

[4] Dewangan, S., Datta, S., Patel, S.K., and Mahapatra S.S., 2011, "A case study on quality and productivity optimization in electric discharge machining," 14 th International Conference in Advanced Materials and Processing Technologies AMPT201113-16 July, Istanbul, Turkey.

[5] Joshi, S, N., and Pande, S.S., 2011, "Intelligent process modelling and optimization of diesinking electric discharge machining," Elsevier, 11(2), pp. 2743-2755.

[6] Mandal, D., Pal, S.K., and Saha, P., 2007, "Modelling of electrical discharge machining process using back propagation neural network and multi-objective optimization using non- 
dominating sorting geneticalgorithm-II," Journal of Materials Processing Technology, 186(1-3), pp. 154-162.

[7] Kim J Seelan, Rajesh R and Liji R. F, Optimization of EDM Parameters Using RSM and Grey Relational Analysis for Aluminium Titanium Diboride (A1-Tib2), International Journal of Mechanical Engineering and Technology, 8(5), 2017, pp. 1022- 1033.

[8] Thella Babu Rao, K. Dinesh Kumar Reddy, K. Bala Srikar, M. Prasanna Krishna and Ch. Pavan Kumar, Simultaneous Optimization of $\mu$-EDM Parameters for Machining Inconel 718 Super Alloy, International Journal of Mechanical Engineering and Technology, 9(5), 2018, pp. 436-444. 